\title{
Numerical and Experimental Research on the Effect of Platform Heave Motion on Vortex-Induced Vibration of Deep Sea Top-Tensioned Riser
}

\author{
Jie Zhang $\mathbb{D}^{1,2}$ Ying Zeng, ${ }^{1}$ Yougang Tang, ${ }^{3}$ Wenyun Guo $\mathbb{D},{ }^{1}$ and Zhenkui Wang $\mathbb{D}{ }^{3,4}$ \\ ${ }^{1}$ College of Ocean Science and Engineering, Shanghai Maritime University, Shanghai 201306, China \\ ${ }^{2}$ Department of Civil, Environmental and Geomatic Engineering, University College London, London, WC1E 6BT, UK \\ ${ }^{3}$ State Key Laboratory of Hydraulic Engineering Simulation and Safety, Tianjin University, Tianjin 300072, China \\ ${ }^{4}$ State Key Laboratory of Ocean Engineering, Shanghai Jiaotong University, Shanghai 200240, China
}

Correspondence should be addressed to Jie Zhang; zhangjie@shmtu.edu.cn

Received 31 March 2020; Revised 25 February 2021; Accepted 3 March 2021; Published 17 March 2021

Academic Editor: Marco Lepidi

Copyright (c) 2021 Jie Zhang et al. This is an open access article distributed under the Creative Commons Attribution License, which permits unrestricted use, distribution, and reproduction in any medium, provided the original work is properly cited.

\begin{abstract}
The prediction and control of vortex-induced vibration (VIV) is one of the key problems for riser design. The effect of platform heave motion on VIV of deep sea top-tensioned riser (TTR) is presented by means of numerical simulation and experiment in this research. First, the heave motion was modeled as a parametric excitation, and the governing equation of VIV of riser considering the parametric excitation was established. Then, the dynamic response of TTR was calculated numerically by the finite difference method based on the Van der Pol wake-oscillator model. Finally, a validation experiment was carried out at the towing tank of Tianjin university. The results show that the VIV response at the bottom of riser is significantly increased due to the platform heave motion, especially in the situation of low current velocity. The larger amplitude and the higher frequency of the platform heave motion with the greater influence are generated on VIV of TTR. In particular, the value of 0.5 times, 1 time, or other multiples of the platform heave frequency will be included in the vibration frequency component of TTR when the platform heave amplitude is large and the frequency is high.
\end{abstract}

\section{Introduction}

With the growing demand of oil and gas, offshore oil and gas explorations are moving into deeper waters. A marine riser, an essential component of subsea oil/gas production systems, acts as a conductor pipe between a wellhead at the sea bed and an offshore floating platform, as shown in Figure 1. The riser is connected to the wellhead through the blowout preventer (BOP) valve that prevents leakages of the fluid transported through the riser. The riser system is exposed to harsh environmental loads like ocean currents and waves. The currents act along the length of the riser, which usually caused vortex-induced vibration (VIV) whereas the waves inflict the movements of the platform (such as surge and heave). A severe current and a large movement of the platform can result in a large deflection of the riser, which causes a disconnection of the riser from the BOP valve or a failure due to fatigue in the riser system [1].

VIV is a fluid-structure interaction phenomenon experienced by a large variety of slender marine structures subjected to current. Drilling and production risers are mostly affected by VIV, which is a direct consequence of lift and drag oscillations due to the vortex-shedding formation behind risers [2]. Waves and vessel motions related damage to the riser will diminish as water depth increases, but currents can act over the full water depth, tending to make VIV more important in deeper water [3]. An overview on the basic VIV phenomenon and empirical models relevant for slender marine structures is found in $[1,4-6]$. The prediction of VIV of deep sea riser was a challenging task since the incident current was practically nonuniform and the associated fluid-structure interaction phenomena were highly 


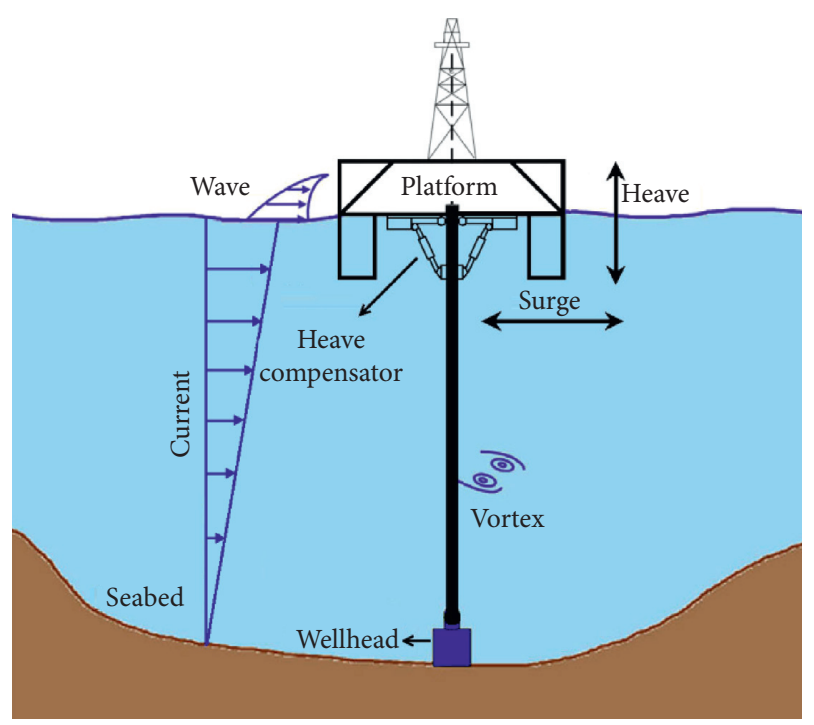

FIGURE 1: Schematic of a top-tensioned riser in ocean environment.

complex. Many investigations on VIV have been substantial in the past, both experimentally and numerically [7, 8]. Traditionally the cross-flow vibrations have been given most attention among researchers. This is probably due to significantly larger response amplitudes than what is observed in the in-line direction [9]. However, in later years, in-line vibrations and the combination of cross-flow and in-line VIV have become a larger focus area [9-12].

The top of the riser is connected with the platform which has motions (surge and heave) in ocean waves. Such motions will cause a displacement on the top of the riser and result in changes of the riser dynamic performance. Chen et al. [13] studied the dynamic response of the riser suffering both the floating top end and VIV. An integrated system with both platform and riser was established by means of finite element numerical simulations. The result showed that the displacement of the riser was multiple times larger than that of the case without moving top end. In the process of studying VIV, Guo et al. [14] found that the dynamic response of the top-tensioned riser (TTR) in the upper part was much larger due to the platform surge motion. Meanwhile, Fan et al. [15] pointed out that the platform surge had a great influence on the hang-off drilling riser, especially resulted in the larger displacement and stress on the bottom of the riser. Wang et al. [16] and Yin et al. [17] performed experiments in towing tank for TTR which was excited at the top by platform surge motion, and the results showed that the platform surge had a great influence on VIV of TTR. The platform heave motion was applied as a moving boundary condition at the top of the riser. Gao [18] found that the displacement and stress of the riser in the upper part are much larger. In general, if taking heave motions, it introduces a fluctuating tension of riser, which presents a periodically varying structural property. Wang and Ling [19] indicated that the tension fluctuation due to top-end heave may introduce new riser's VIV involving higher-order modes and larger dynamic responses, e.g., riser's displacement and shear stress are, respectively, $10 \%$ and $20-100 \%$ larger than the case without heave motion. Thorsen and Sævik [20] presented an investigation on how tension variations affect the VIV response. They concluded that when the riser top end oscillates, the VIV response contains several modes, and the dominating mode may vary with time. The number of active modes was found to be strongly dependent on the period of the riser tension. Although this fluctuation tension is generally significantly reduced by heave compensators, it still might destabilize the straight equilibrium of the riser and cause it to vibrate at a dangerously high level [21, 22].

Recently, we studied the effect of top tension on VIV of deep sea top-tensioned riser (TTR) and presented a VIV prediction model of TTR in linearly sheared current by numerical simulation and experiment [23]. For an advanced research, this paper is to investigate the dynamic behavior of TTR under VIV and platform heave motion. The platform heave motion is modeled as a parametric excitation on the top of TTR.

\section{Governing Equations}

The top end of TTR is connected with the platform by the heave compensator (see Figure 1). The compensator provides a large static tensile tension at the top of TTR, and the pretension is generally 1.1-1.6 times of the weight of TTR, which can keep TTR vertical and avoid buckling due to its large length. In addition, the compensator has the buffering function as a spring on the riser to reduce the platform heave motion effect. In this research, the heave compensator is modeled as a pretension vertical spring with a stiffness which is much lower than the axial stiffness of TTR. At the bottom end, the connection between the riser and the wellhead is modeled by a hinge, as shown in Figure 2. The sea current is in $y$ direction and simplified as shear current.

The motion equation governing the transverse displacement $x(z, t)$ of TTR from its straight vertical equilibrium as a function of depth $z$ and time $t$ can be written as follows:

$$
\mathrm{EI} \frac{\partial^{4} x(z, t)}{\partial z^{4}}-\frac{\partial}{\partial z}\left[T(z, t) \frac{\partial x(z, t)}{\partial z}\right]+\bar{m} \frac{\partial^{2} x(z, t)}{\partial t^{2}}=f_{x}(z, t),
$$

where EI is the bending stiffness of the riser, $\bar{m}$ is the mass per unit length of the system (riser with internal fluid and added mass), and $T(z, t)$ is the effective tension in the riser.

$$
T(z, t)=T_{t}-W_{a} z+K a \cos (\Omega t)
$$

where $T_{t}$ is the tension at the top end of TTR, $T_{t}=f_{\text {top }} W_{a} z$, $f_{\text {top }}$ is a dimensionless pretension factor which varies between 1.1 and 1.6 (in this paper, $f_{\text {top }}=1.3$ ), $W_{a}$ is the submerged weight of the riser per unit length, $K$ is the stiffness of the heave compensator, $K=\left(W_{a} L / 10\right)$ [21], and $a$ and $\Omega$ are the amplitude and the frequency of platform heave motion.

Equation (2) shows that the effective tension in riser has static and dynamic components. The static component of the tension comes from the pretension imposed by the heave 


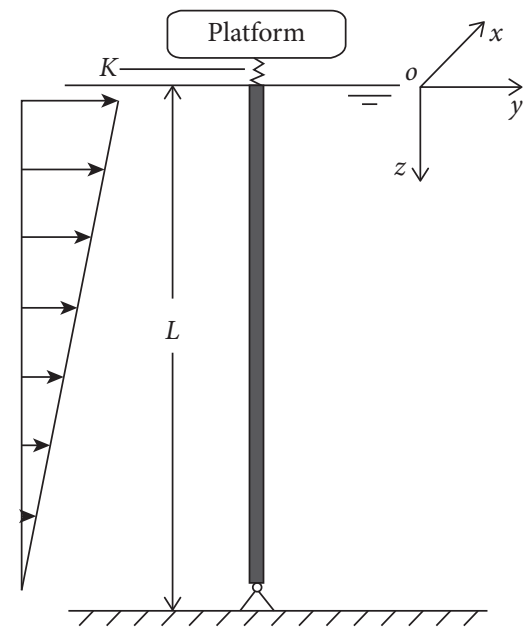

Figure 2: Simply supported TTR.

compensator and submerged weight. The dynamic component of the tension is caused by the heaving platform, and $(\Omega, a)$ is generally referred to as parametric excitations for the transverse vibration of TTR $[21,22]$. Therefore, equation (1) is a partial differential equation with periodic variable coefficient, and this is different from the partial differential equation with constant variable coefficient in [23].

$f_{x}(z, t)$ is the hydrodynamic force per unit length of the riser. Generally, $f_{x}(z, t)$ is calculated by Morison's equation:

$$
f_{x}(z, t)=\frac{1}{2} \rho_{w} D C_{L} U^{2}-\frac{1}{2} \rho_{w} D C_{d}|\dot{x}| \dot{x}
$$

where $\rho_{w}$ is the density of seawater, $D$ is the outer diameter of the riser, $C_{L}$ is the lift force coefficient, $U$ is the current velocity in any depth, $U=(1-(z / L)) U_{0}, U_{0}$ is the current velocity at sea level, and $C_{d}$ is the drag coefficient.

A forced Van der Pol oscillator equation is used to describe the dynamics of the riser's wake [24]:

$$
\ddot{q}+\varepsilon \Omega_{f}\left(q^{2}-1\right) \dot{q}+\Omega_{f}^{2} q=F,
$$

where the variable $m$ is defined as the local fluctuating lift coefficient, $q=\left(2 C_{L} / C_{L 0}\right)$, the reference lift coefficient $C_{L 0}$ is that observed on a fixed structure subjected to vortex shedding, and $\Omega_{f}$ is the vortex-shedding frequency, which is related to the nondimensional Strouhal number $S_{t}$, $\Omega_{f}=\left(2 \pi S_{t} U / D\right)$. It is common practice to assume $S_{t}=0.2$ in the subcritical range, $300<R_{e} \prec 1.5 \times 10^{5}$. The reference lift coefficient $C_{L 0}$ is usually taken as $C_{L 0}=0.3$ in the large range of $R_{e}$. The right hand side forcing term $F$ models the effect of the cylinder motion on the near wake, $F=(A \ddot{x} / D)$. The coupling and interaction between the fluid and the structure are captured through the excitation term $F$. $\varepsilon$ and $A$ are wake and coupling empirical coefficients, respectively. The assumed empirical coefficients are based on calibration with experimental results of elastically mounted rigid cylinders. These parameters are related to the intrinsic wake dynamics, and higher values of $\varepsilon$ and $A$ mean a wider lock-in domain. In most studies, the proposed parameters are adopted as $\varepsilon=$ 0.3 and $A=12$ [24-26].

According to equations (1)-(4), the governing equation of VIV of TTR considering the platform heave is written as follows:

$$
\left\{\begin{array}{l}
\mathrm{EI} \frac{\partial^{4} x(z, t)}{\partial z^{4}}-\frac{\partial}{\partial z}\left[\left(T_{t}-w z+K a \cos (\Omega t)\right) \frac{\partial x(z, t)}{\partial z}\right]+\bar{m} \frac{\partial^{2} x(z, t)}{\partial t^{2}}=\frac{1}{4} \rho_{w} D C_{L 0} \eta U^{2}-\frac{1}{2} \rho_{w} D C_{D}|\dot{x}| \dot{x} \\
\ddot{q}+\varepsilon \Omega_{f}\left(q^{2}-1\right) \dot{q}+\Omega_{f}^{2} q=\frac{A}{D} \ddot{x} .
\end{array}\right.
$$

Assuming that the connection between the heave compensator and the riser can be modeled as a hinge, the boundary conditions at the ends of the riser are given as follows:

$$
x(z, t)=0, \frac{\partial^{2} x(z, t)}{\partial z^{2}}=0, \quad(z=0, z=L) .
$$

\section{Numerical Examples}

3.1. System Parameters and Basic Calculations. The adopted values of the system parameters are shown in Table 1. It should be pointed out that the data in Table 1 are from the Truss Spar (named Horn Mountain) servicing in the Gulf of Mexico [27].

The $n$th natural frequency is given as follows [28]:

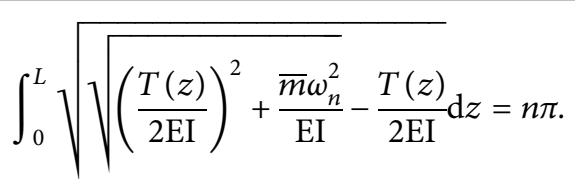

The $n$th mode function for the low modes is given by Zhang and Tang [28]:

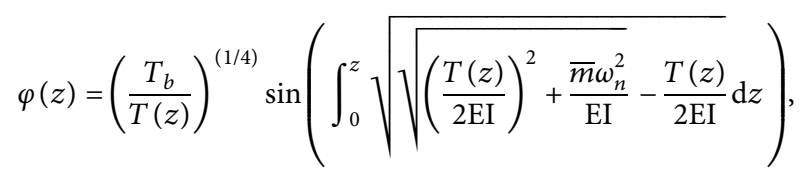

where $T_{b}$ is the tension at the bottom of the riser.

The natural frequencies of TTR are shown in Table 2. It shows that the low-order natural frequencies of TTR are small. The $n$th natural frequency is about $n$ times of the first frequency. The reason is that owing to the high slenderness ratio of TTR, the lower modes are mainly affected by tension 
TABLE 1: Base set of system parameters.

\begin{tabular}{lcccc}
\hline No. & Property & Symbol & Value & Unit \\
\hline 1 & Riser length & $L$ & 1500 & $\mathrm{~m}$ \\
2 & Outer diameter & $D$ & 0.3048 & $\mathrm{~m}$ \\
3 & Wall thickness & $t$ & 0.0136 & $\mathrm{~m}$ \\
4 & Young's modulus & $E$ & $2.1 \mathrm{E} 11$ & $\mathrm{~Pa}$ \\
5 & Density of steel & $\rho_{s}$ & 7850 & $\mathrm{~kg} / \mathrm{m}^{*} 3$ \\
6 & Density of seawater & $\rho_{w}$ & 1025 & $\mathrm{~kg} / \mathrm{m}^{*} 3$ \\
7 & Density of internal fluid & $\rho_{f}$ & 800 & $\mathrm{~kg} / \mathrm{m}^{*} 3$ \\
8 & Added mass coefficient & $C_{a}$ & 1.0 & - \\
9 & Drag coefficient & $C_{d}$ & 1.0 & - \\
\hline
\end{tabular}

TABLE 2: Natural frequencies of TTR( $\mathrm{rad} / \mathrm{s})$.

\begin{tabular}{lccccccc}
\hline$\omega_{1}$ & $\omega_{2}$ & $\omega_{3}$ & $\omega_{4}$ & $\omega_{5}$ & $\omega_{6}$ & $\omega_{7}$ & $\omega_{8}$ \\
\hline 0.1329 & 0.2659 & 0.3990 & 0.5324 & 0.6661 & 0.8003 & 0.9349 & 1.0701 \\
\hline
\end{tabular}

and the bending stiffness does not have significant effect on the lower modes.

The mode shapes of TTR are obtained according to equation (8), as shown in Figure 3. It can be found that the single mode shape of TTR with variable tension is no longer a standard sine function, and the nodes and antinodes of mode shape are no longer uniformly distributed along the axial direction. The antinode amplitude increases as the depth increases; this leads to a larger mode curvature at the bottom of TTR which has a greater influence on the bending stress.

In general, the designed natural period of Spar varies between $20 \mathrm{~s}$ and $30 \mathrm{~s}$, and the period of ocean waves varies between $4 \mathrm{~s}$ and $9 \mathrm{~s}$. Meanwhile, the amplitude of platform heave motion generally varies between $0.0 \mathrm{~m}$ and $5.0 \mathrm{~m}$ [29]. The platform heave motion was numerically simulated under different ocean conditions by Shen [30]. The results showed that the waves could not cause a large heave motion unless in the case of extreme ocean environment which may cause resonance. Actually, the amplitude of platform heave motion varies between $0.43 \mathrm{~m}$ and $1.56 \mathrm{~m}$ (mean value is $0.61 \mathrm{~m}$ ) according to the field measurements [27]. In conclusion, the range of the amplitude and frequency of platform heave is determined as $a=0 \sim 2 m$ and $\Omega=0.4 \sim$ $1.6 \mathrm{rad} / \mathrm{s}$. It shows that the range is concentrated in the loworder mode frequencies of TTR, and $(\Omega, a)$ as parametric excitations are not in instability zones [22].

3.2. Dynamic Response of TTR. The VIV response of TTR can be calculated numerically by the finite difference method (FDM) according to equation (5). The time history of VIV of TTR at each depth is obtained. Figure 4 shows the displacement and bending stress of TTR with a depth of $1125 \mathrm{~m}$. It can be seen that the displacement and bending stress of TTR are slightly increased due to the platform heave. The VIV characteristics are changed considering the platform heave, especially stress cycle of TTR is changed, which will have a certain impact on the fatigue damage.

The frequency spectrum of TTR is shown in Figure 5. It can be found that the dominant frequency of TTR is more prominent considering the platform heave motion, whereas the components and value of frequency are basically unchanged.

Actually, the effect of platform heave on VIV of TTR is much more complicated than the abovementioned phenomenon. It is related to the severity of platform heave motion, current velocity, and the position of each node in simulation by FDM. Equation (2) shows that the axial tension of TTR decreases gradually with the increase in water depth due to the effect of gravity; therefore, the influence of platform heave on each position of TTR is different. In addition, the excited modes of VIV of TTR in different ocean current are not the same either. In order to carry out a further investigation on the effect of platform heave on VIV of TTR, the VIV response of TTR is obtained under different cases: $a=0 \sim 2 \mathrm{~m}$ and $\Omega=0.4 \sim 1.6 \mathrm{rad} / \mathrm{s}$; the current velocity at sea level generally varies between $0.1 \mathrm{~m} / \mathrm{s}$ and $1 \mathrm{~m} / \mathrm{s}$ without considering influence of waves [31].

3.3. Effect of Platform Heave Amplitude on VIV. Assuming $\Omega=2 \omega_{4}, a$ is $1 \mathrm{~m}, 1.5 \mathrm{~m}$, and $2 \mathrm{~m}$, respectively. According to the time history of displacement and bending stress of each node, the maximum displacement and the maximum bending stress of TTR are obtained, as shown in Figures 6 and 7.

Figure 6 shows the effect of platform heave amplitude on vibration displacement of TTR. (1) In the case of low current velocity, the platform heave motion has a greater influence on the vibration displacement of TTR, and the maximal displacement is at the bottom of the riser. (2) In the case of the high current velocity, the platform heave motion has a smaller influence on the vibration displacement of TTR, and the maximal displacement is at the middle of the riser. (3) For every current velocity, the vibration displacement of TTR is increased due to the platform heave motion, especially, the displacement at the bottom of TTR is significantly increased. The vibration displacement of TTR increases as the platform heave amplitude increases.

Figure 7 shows the effect platform heave amplitude on bending stress of TTR. (1) In the case of low current velocity, the platform heave motion has a greater influence on the bending stress of TTR, and the maximal bending stress is at the bottom of the riser. (2) In the case of high current velocity, the platform heave motion has a smaller influence on the middle-upper bending stress whereas a significant influence on the bottom bending stress of TTR, and the maximal bending stress is at the bottom of the riser. (3) For every current velocity, the bending stress of TTR is increased due to the platform heave motion, especially the bending stress at the bottom of TTR is significantly increased. The bending stress of TTR increases as the depth increases and also increases as the platform heave amplitude increases.

The reason of this phenomenon is that the vortexshedding frequency is close to the low-order natural frequency of TTR in the lower current; hence, the low-order modes are excited. The amplitude of low modes is large; however, the mode curvature is small. Therefore, the vibration displacement is large but the bending stress is small 


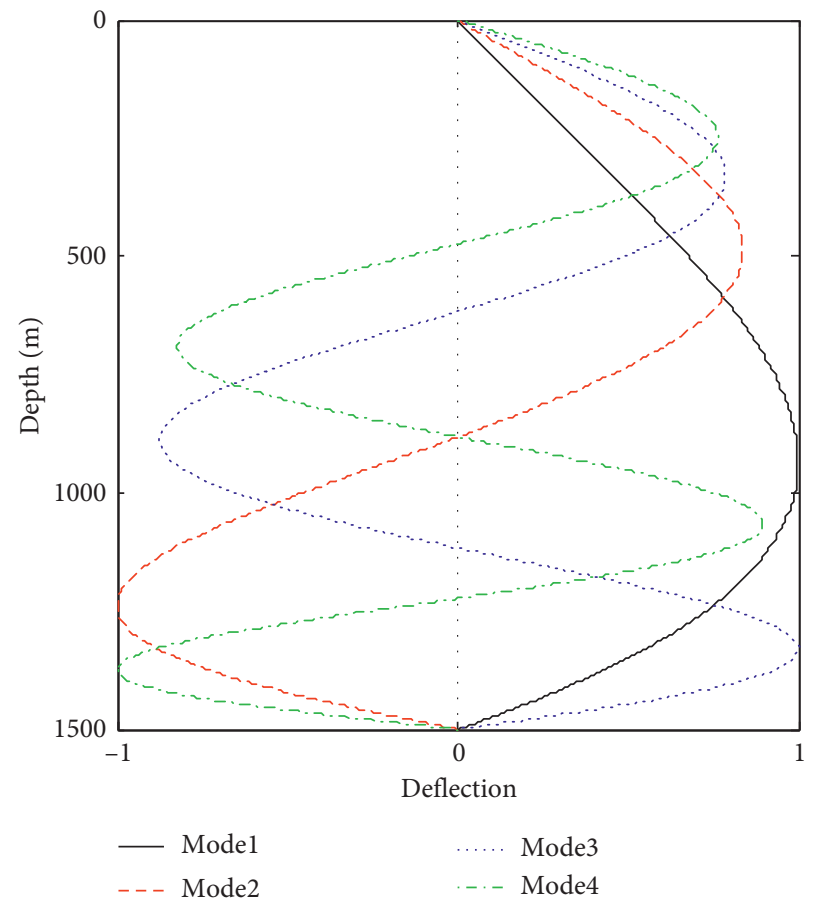

Figure 3: Mode shapes of TTR.

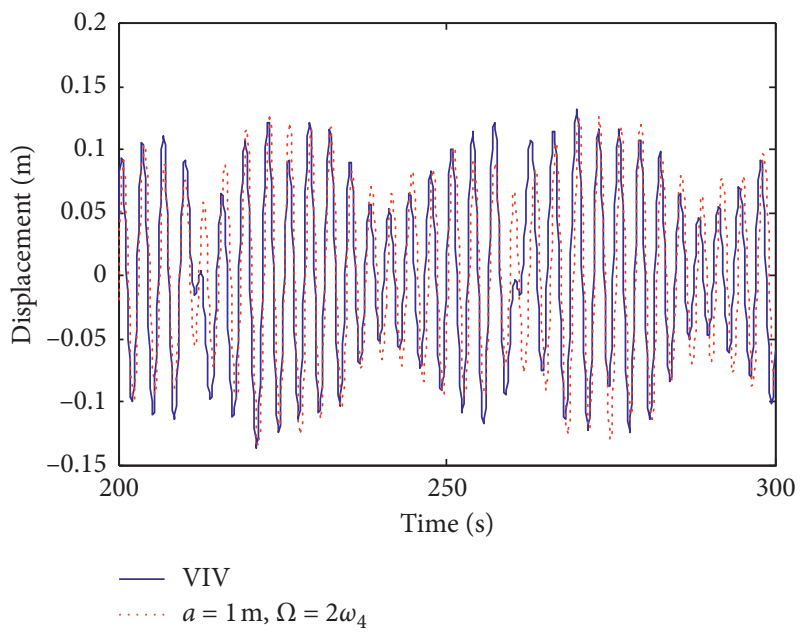

(a)

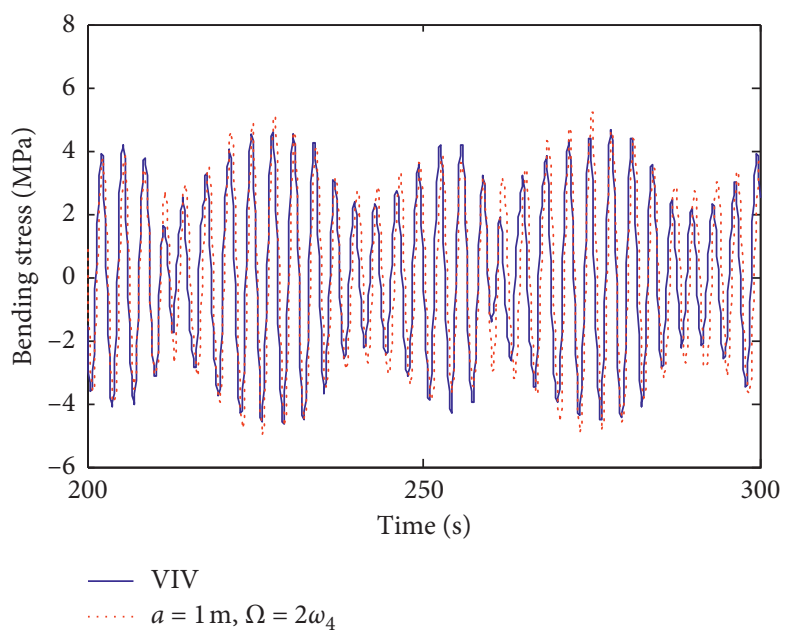

(b)

Figure 4: Dynamic response of TTR $\left(U_{0}=0.5 \mathrm{~m} / \mathrm{s}\right.$ and $\left.z=1125 \mathrm{~m}\right)$. (a) Time history of displacement. (b) Time history of bending stress.

in the case of low current velocity. The platform heave motion induces a fluctuation in the axial tension of TTR, especially, the tension in riser bottom is greatly influenced, since the axial tension decreases as the depth increases due to the gravity. Therefore, the vibration response of TTR at the bottom is greatly influenced by the platform heave motion.

Comparing Figure 6 with Figure 7, the change trend of vibration displacement and bending stress is inconsistent, and it shows that the bending stress is determined by the secondderivative of displacement, not by the displacement.
3.4. Effect of Platform Heave Frequency on VIV. Assuming $a=1 \mathrm{~m}, \Omega$ is $2 \omega_{2}, 2 \omega_{4}$, and $2 \omega_{6}$, respectively. The maximum displacement and the maximum bending stress of TTR are shown in Figures 8 and 9.

Figure 8 shows the effect of platform heave frequency on vibration displacement of TTR. (1) In the case of low current velocity, the frequency of platform heave motion has a greater influence on the vibration displacement of TTR. (2) In the case of high current velocity, the frequency of platform heave motion has a smaller influence on the vibration displacement of TTR. 


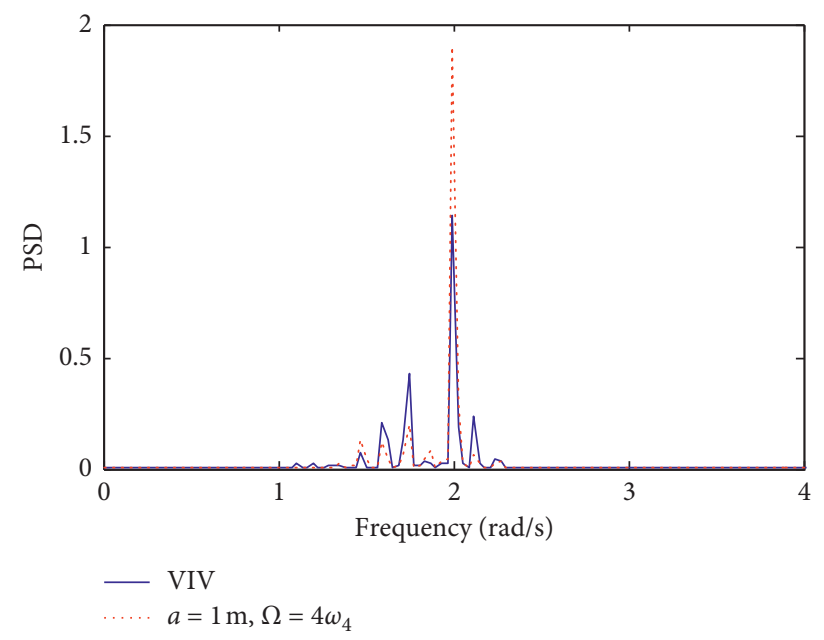

Figure 5: Frequency spectrum of TTR $\left(U_{0}=0.5 \mathrm{~m} / \mathrm{s}\right)$.

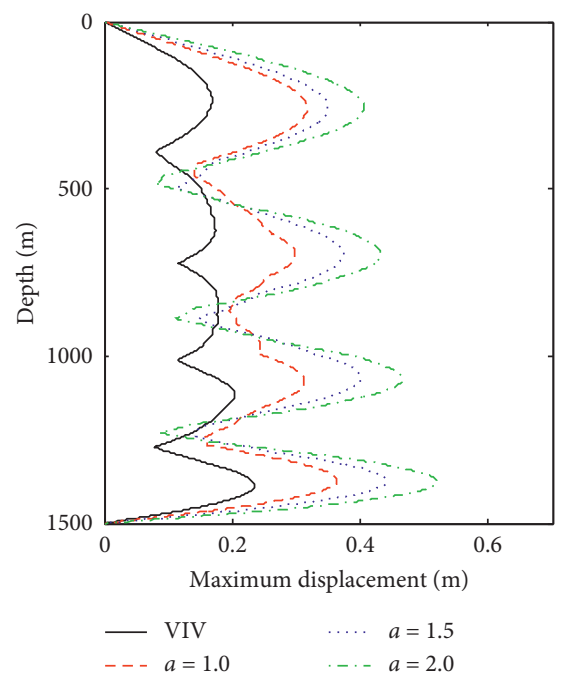

(a)

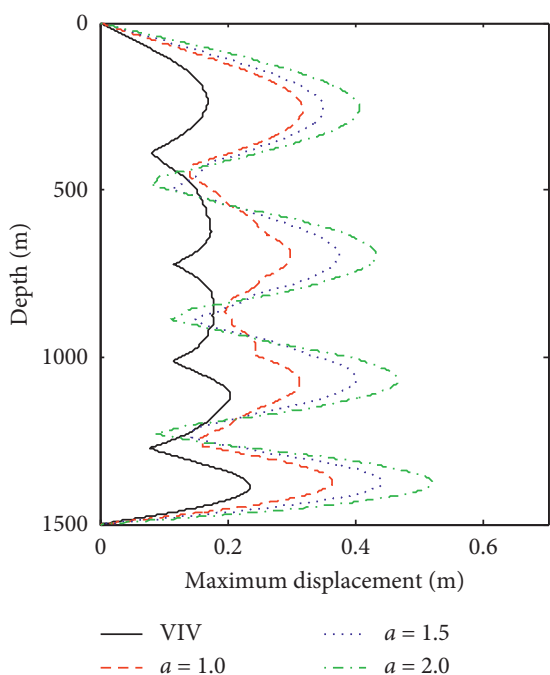

(b)

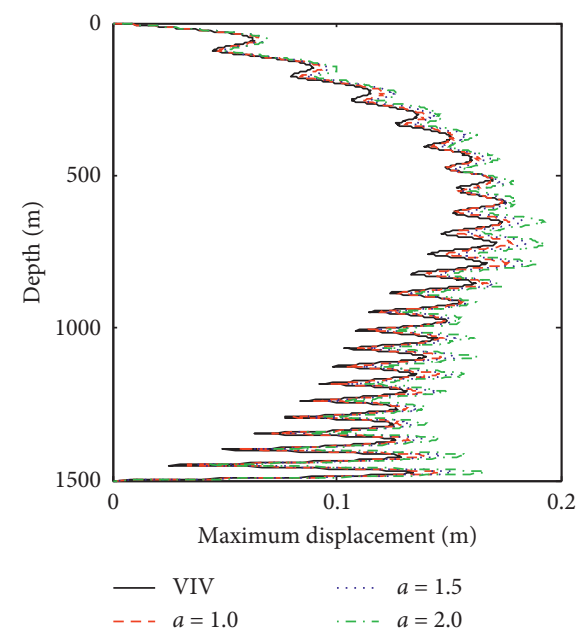

(c)

Figure 6: The maximum displacement of TTR $\left(\Omega=2 \omega_{4}\right.$ ): (a) $U_{0}=0.2 \mathrm{~m} / \mathrm{s}$; (b) $U_{0}=0.5 \mathrm{~m} / \mathrm{s}$; (c) $U_{0}=0.8 \mathrm{~m} / \mathrm{s}$.

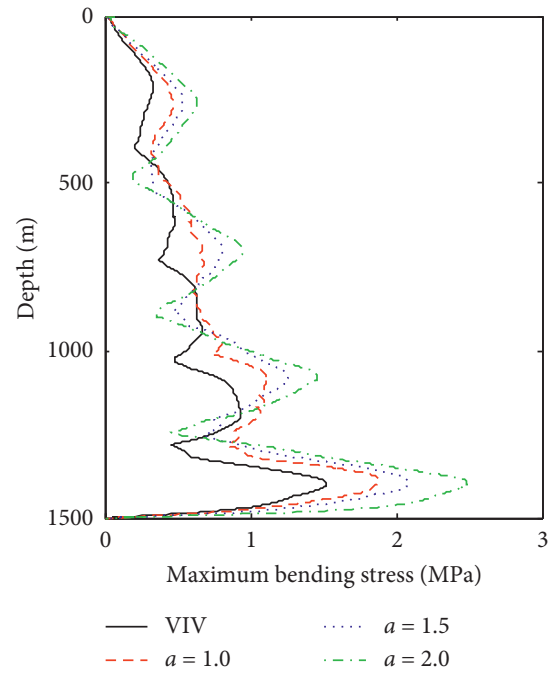

(a)

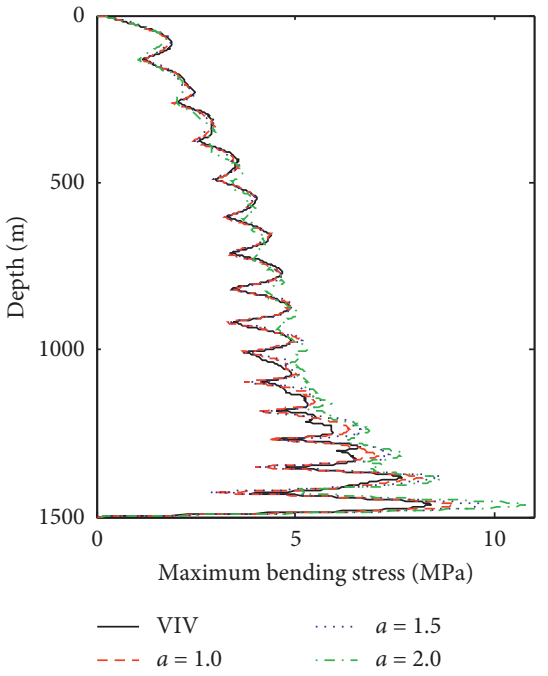

(b)

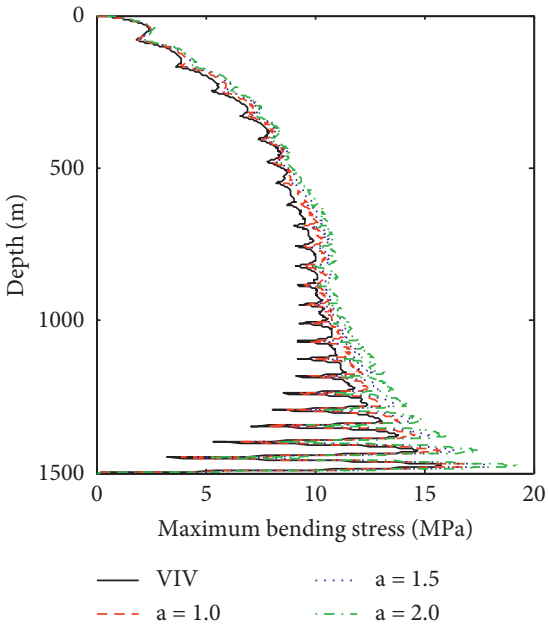

(c)

FIgURE 7: The maximum bending stress of TTR $\left(\Omega=2 \omega_{4}\right.$ ): (a) $U_{0}=0.2 \mathrm{~m} / \mathrm{s}$; (b) $U_{0}=0.5 \mathrm{~m} / \mathrm{s}$; (c) $U_{0}=0.8 \mathrm{~m} / \mathrm{s}$. 


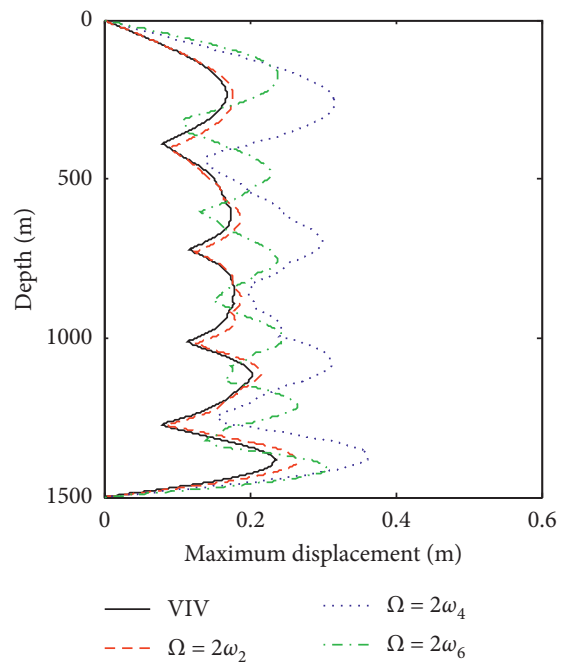

(a)

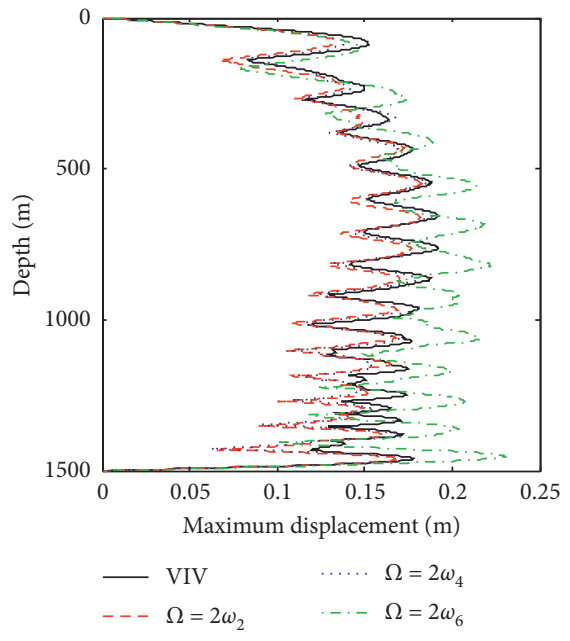

(b)

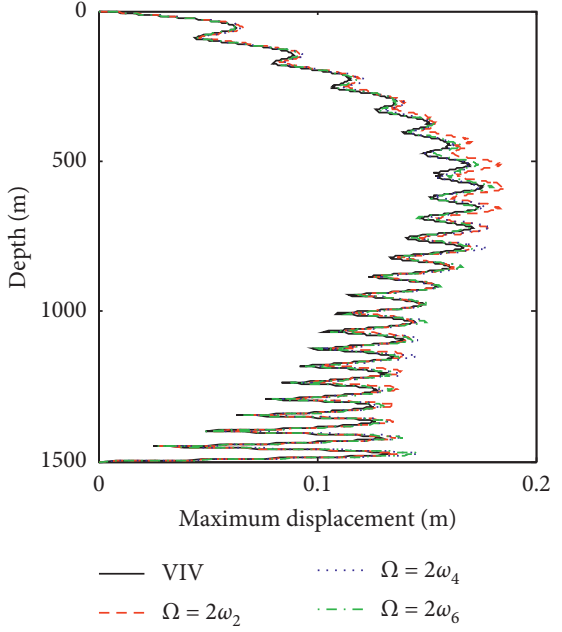

(c)

Figure 8: The maximum displacement of TTR $(a=1 \mathrm{~m})$ : (a) $U_{0}=0.2 \mathrm{~m} / \mathrm{s}$; (b) $U_{0}=0.5 \mathrm{~m} / \mathrm{s}$; (c) $U_{0}=0.8 \mathrm{~m} / \mathrm{s}$.

(3) The effect of platform heave frequency on vibration displacement of TTR is complex, which is related to the relationship among the riser natural frequency, vortex-shedding frequency, and platform heave frequency. A further discussion on this relationship is provided in Section 3.5.

Figure 9 shows the effect of platform heave frequency on bending stress of TTR. (1) In the case of low current velocity, the frequency of platform heave motion has a greater influence on the bending stress of TTR, and the bending stress increases as the platform heave frequency increases. (2) In the case of high current velocity, the frequency of platform heave has a smaller influence on the bending stress of TTR.

3.5. Dominant Frequencies of VIV of TTR. The dominant vibration frequencies of TTR under different cases are shown in Table 3.

Table 3 shows the following. (1) In the case of low current, the dominant frequency of TTR is about 0.5 times (yellow area) or 1 time (green area) of the platform heave frequency when the platform heave amplitude is large and the frequency is high. At this case, TTR is mainly controlled by platform heave motion. This phenomenon is called parametric resonance, which leads to significant increase in vibration response, as shown in Figures 6(a) and 7(a). When the platform heave amplitude is small or the frequency is low, the dominant vibration frequency of TTR is barely affected. At this case, TTR is mainly controlled by VIV. (2) In the case of high current velocity, the platform heave has a smaller influence on the dominant vibration frequency of TTR. At this case, TTR is mainly controlled by VIV.

The reason of this phenomenon is that the platform heave frequency is close to the low-order natural frequency of TTR and the low-order mode vibration is greatly influenced, whereas the high-order mode vibration in higher current is less affected.

It should be pointed out that the level of current velocity is relative; this is related to the sea depth which determines the length and natural frequency of the riser. On the one hand, VIV is inherently complex. When the vortex-shedding frequency is close to one of the natural frequencies of the riser, large amplitude resonant response occurs, called as lock-in. Lock-in behavior is well documented in uniform current. However the occurrence of lock-in in deep sea with sheared currents is complicated with the fact that the resonant responses at different axial locations may be in different modes and the excited modes compete with each other. Even the current velocity is small, the VIV response may be large when lock-in occurs. On the other hand, the vibration modes will increase under the parametric excitations. The influence of parametric excitations on each mode is not the same. In some cases, the vibration is locked at a specific frequency which is related to platform heave frequency called as parametric resonance which leads to significant increase in vibration response. Sometimes it is hard to say whether the VIV resonance response is larger or the parametric resonance response is larger. Therefore, the relationship among the platform heave frequency, vortexshedding frequency (current velocity), riser natural frequency, and platform heave amplitude determines the final vibration modes and response.

\section{VIV Experiment with the Platform Heave Motion}

4.1. Test Introduction. The top end of the riser was designed with variable top tension by a spring and a linkage device, as shown in Figure 10. The top tension has static and dynamic components.

$$
T=T_{t}+\Delta T \cos (2 \pi \Omega t)
$$

where $T_{t}$ is the pretension which is constant and $\Delta T \cos (2 \pi \Omega t)$ is the variable tension which comes from the linkage device with adjustable frequency and stroke, and it is used to simulate the action on the riser from the platform 


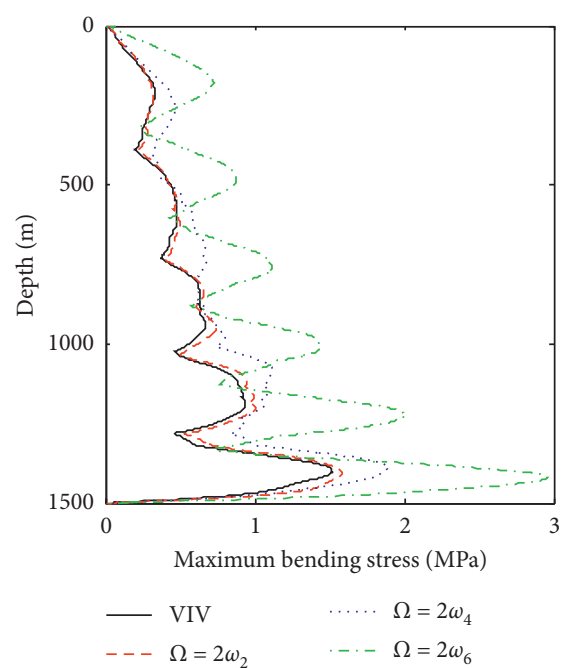

(a)

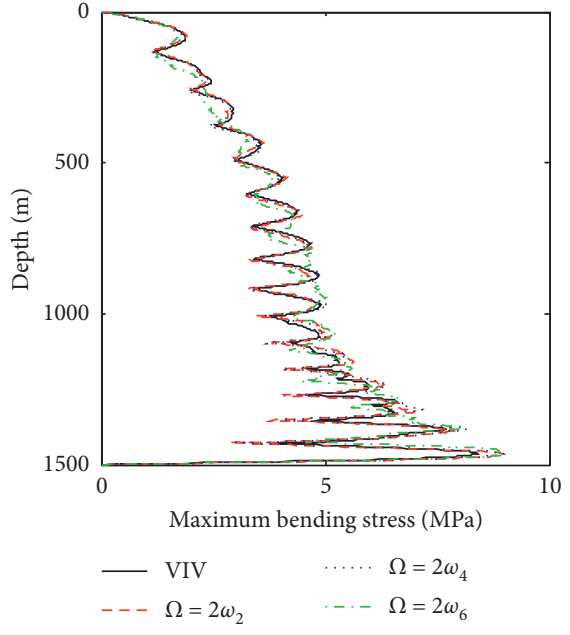

(b)

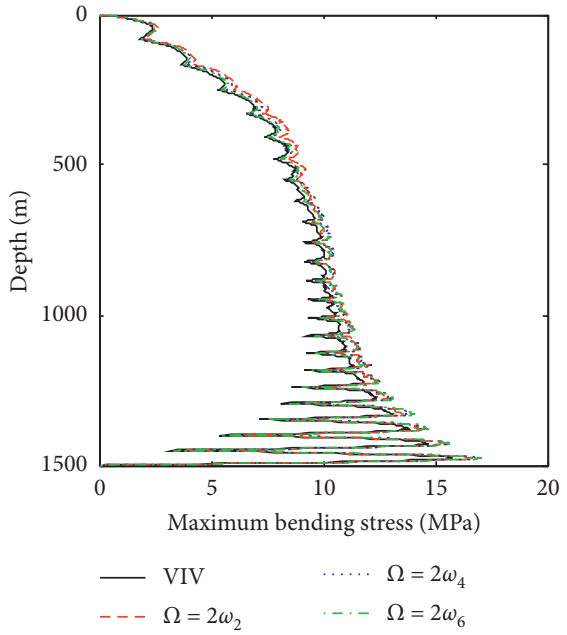

(c)

Figure 9: The maximum bending stress of TTR $(a=1 \mathrm{~m})$ : (a) $U_{0}=0.2 \mathrm{~m} / \mathrm{s}$; (b) $U_{0}=0.5 \mathrm{~m} / \mathrm{s}$; (c) $U_{0}=0.8 \mathrm{~m} / \mathrm{s}$.

TABlE 3: Dominant frequencies of TTR ( $\mathrm{rad} / \mathrm{s})$.

\begin{tabular}{lccccccccc}
\hline $\begin{array}{l}\text { Current } \\
\text { velocity }(\mathrm{m} / \mathrm{s})\end{array}$ & VIV & \multicolumn{4}{c}{$\Omega=1.0648(2 \omega 4)$} \\
\hline 0.1 & & $a=0.5 \mathrm{~m}$ & $a=1 \mathrm{~m}$ & $a=1.5 \mathrm{~m}$ & $a=2 \mathrm{~m}$ & $\Omega=0.5318(2 \omega 2)$ & $\Omega=0.7980(2 \omega 3)$ & $\Omega=1.3322(2 \omega 5)$ & $\Omega=1.6006(2 \omega 6)$ \\
0.2 & 0.2654 & 0.2655 & 0.2655 & 0.5321 & 0.5324 & 0.2653 & 0.3991 & 0.6654 \\
0.3 & 0.6440 & 0.6749 & 0.6440 & 0.5217 & 0.5215 & 0.6442 & 0.6442 & 0.6746 \\
0.4 & 1.0433 & 1.0428 & 0.9205 & 1.0592 & 1.0736 & 1.0431 & 1.0431 & 1.0433 \\
0.5 & 1.1966 & 1.3196 & 1.4728 & 1.1966 & 1.0729 & 1.3196 & 1.1966 & 1.3357 \\
0.6 & 1.9942 & 1.9943 & 1.9943 & 1.9943 & 1.9943 & 1.9944 & 1.9941 & 1.9943 \\
0.7 & 2.4237 & 2.4327 & 2.4327 & 2.4327 & 2.3939 & 2.4327 & 2.4327 & 2.4327 \\
0.8 & 2.8532 & 2.8533 & 2.8531 & 2.8531 & 2.8225 & 2.8531 & 2.8531 & 2.8531 & 0.7674 \\
& 3.1598 & 3.1599 & 3.1598 & 3.2829 & 3.2829 & 3.1601 & 3.1599 & 3.1599 \\
\hline
\end{tabular}

heave. The variable tension frequency $(\Omega)$ is realized by controlling the motor speed with the frequency controller. The variable tension amplitude $(\Delta T)$ is achieved by controlling the shaft radius which is equivalent to changing the spring length.

This experiment was carried out at the towing tank of Tianjin university $(137 \times 7 \times 3 \mathrm{~m})$. The TTR model was placed horizontally due to the limitation of the depth of tank, and the riser was hung at the bottom and moved at a constant speed in the towing tank. The stress of TTR at the midpoint was monitored by use of strain gauges.

The TTR model was made of Teflon, and the parameters of the model are shown in Table 4. The test conditions are shown in Table 5.

The first five natural frequencies of the riser model under different pretension are shown in Table 6. The design of the current velocity and the platform heave frequency in experiment is referred to the natural frequency of the TTR model $(T=100 \mathrm{~N})$.
After the comparison between numerical simulations and experiments, it is proved that the calculating program is reliable [23].

4.2. Effect of Platform Heave Amplitude on VIV. The current velocity in experiment is $0.3 \mathrm{~m} / \mathrm{s}$ and $0.5 \mathrm{~m} / \mathrm{s}$, respectively. The static pretension at the top of TTR is $100 \mathrm{~N}$. The frequency of the periodic variable tension is $\Omega=3 \mathrm{~Hz}$ (approximately equal to 2 times of the first-order natural frequency of TTR). The amplitude of the periodic variable tension is $20 \mathrm{~N}$ and $30 \mathrm{~N}$, respectively.

The bending stress time history of TTR at midpoint is shown in Figure 11. It indicates that the VIV stress of TTR is further aggravated considering the platform heave motion, especially in the case of lower current velocity. The bending stress of riser increases with the increase in platform heave amplitude, which is consistent with the conclusion of numerical calculation in Figure 7. 


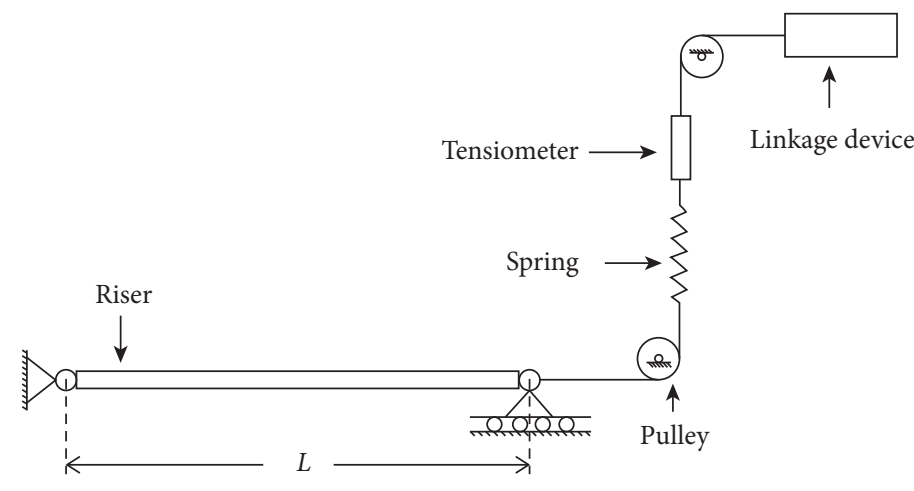

(a)

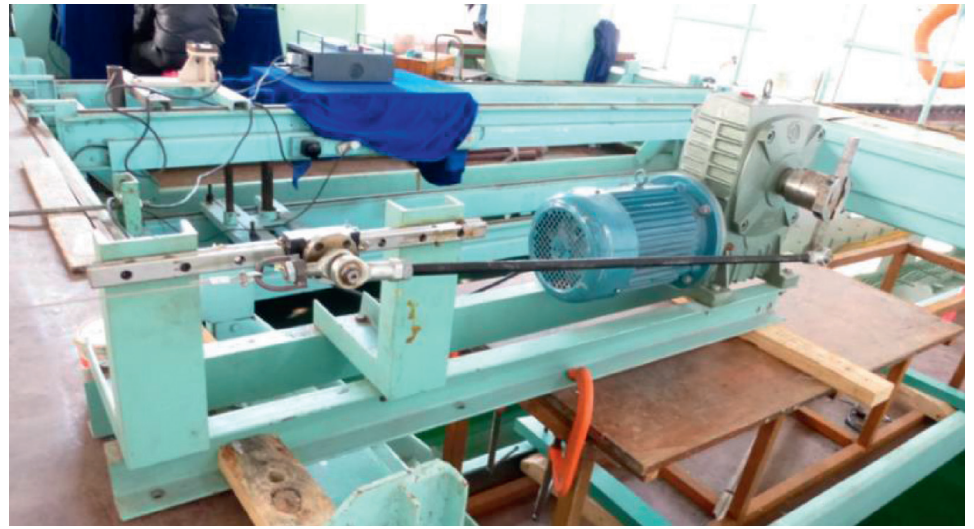

(c)

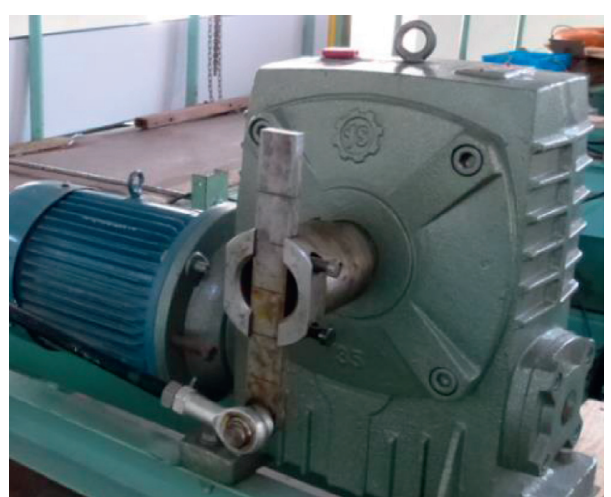

(b)

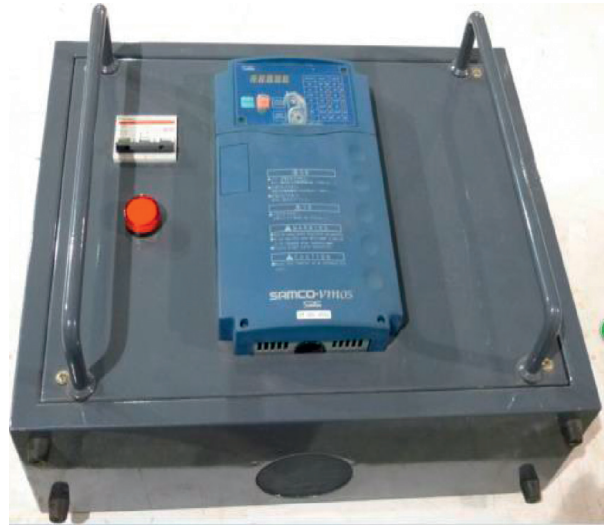

(d)

FIgURE 10: VIV test of TTR considering the platform heave motion. (a) Sketch of the test. (b) The linkage device. (c) Variable stroke. (d) Frequency control instrument.

TABLE 4: Specifications of the riser model.

\begin{tabular}{lccc}
\hline No. & Property & Value & \\
\hline 1 & Length & 5 & $\mathrm{Unit}$ \\
2 & Outer diameter & 0.016 & $\mathrm{~m}$ \\
3 & Wall thickness & 0.001 & $\mathrm{~m}$ \\
4 & Young's modulus & $7.38 \mathrm{E} 8$ & $\mathrm{~m}$ \\
5 & Material & Teflon & $\mathrm{Pa}$ \\
6 & Density of teflon & 2178 & $\mathrm{~kg} / \mathrm{m} * 3$ \\
7 & Density of seawater & 1000 & $\mathrm{~kg} / \mathrm{m} * 3$ \\
8 & Density of internal fluid & 1000 & $\mathrm{~kg} / \mathrm{m} * 3$ \\
\hline
\end{tabular}

The frequency spectrum of TTR is shown in Figure 12. It can be found that the dominant vibration frequency of TTR does not change significantly, especially in the high current. It means that TTR is mainly controlled by VIV in these cases whereas the platform heave frequency $(3 \mathrm{~Hz})$ appears obviously in the components of vibration frequencies, and 0.5 times of the platform heave frequency $(1.5 \mathrm{~Hz})$ or other values are also can be found in Figure 12(b). It indicates that the frequency components of VIV of TTR change due to the platform heave motion, which brings change to the cycles of vibration stress, leading to significant influence on the fatigue damage of TTR. Actually, the effect of platform heave on vibration frequency of TTR is complex, which is related to the relationship among the riser natural frequency, current velocity (vortex-shedding frequency), and the intensity of platform heave.
In addition, the natural frequency of TTR has a periodic microvariation due to the platform heave motion (see Table 6), and it may bring a change in resonance conditions of TTR $[20,28]$. The phenomenon that appears in the experiment is that the vibration frequency components of TTR are more diverse and complex.

4.3. Effect of Platform Heave Frequency on VIV. The VIV response of TTR in the case of different frequencies of platform heave motion is shown in Figures 13 and 14.

Figure 13 shows that the bending stress of TTR increases as the platform heave frequency increases. The effect of platform heave frequency on VIV stress of TTR diminishes as the current velocity increases.

Figure 14 shows that the platform heave frequency appears obviously in the components of vibration 
TABle 5: Test conditions.

\begin{tabular}{lcccc}
\hline No. & Current velocity $(\mathrm{U})$ & Pretension $(\mathrm{Tt})(\mathrm{N})$ & \multicolumn{2}{c}{ Variable tension } \\
\hline 1 & $0.3 \mathrm{~m} / \mathrm{s}$ & 100 & 0 & 0 \\
2 & $0.5 \mathrm{~m} / \mathrm{s}$ & 100 & 0 & 0 \\
3 & $0.3 \mathrm{~m} / \mathrm{s}$ & 100 & $20 \mathrm{~N}$ & $1 \mathrm{~Hz}$ \\
4 & $0.3 \mathrm{~m} / \mathrm{s}$ & 100 & $20 \mathrm{~N}$ & $3 \mathrm{~Hz}$ \\
5 & $0.3 \mathrm{~m} / \mathrm{s}$ & 100 & $30 \mathrm{~N}$ & $1.5 \mathrm{~Hz}$ \\
6 & $0.3 \mathrm{~m} / \mathrm{s}$ & 100 & $30 \mathrm{~N}$ & $3 \mathrm{~Hz}$ \\
7 & $0.5 \mathrm{~m} / \mathrm{s}$ & 100 & $20 \mathrm{~N}$ & $1 \mathrm{~Hz}$ \\
8 & $0.5 \mathrm{~m} / \mathrm{s}$ & 100 & $20 \mathrm{~N}$ & $3 \mathrm{~Hz}$ \\
9 & $0.5 \mathrm{~m} / \mathrm{s}$ & 100 & $30 \mathrm{~N}$ & $1.5 \mathrm{~Hz}$ \\
10 & $0.5 \mathrm{~m} / \mathrm{s}$ & 100 & $30 \mathrm{~N}$ & $3 \mathrm{~Hz}$ \\
\hline
\end{tabular}

TABLE 6: Natural frequencies of the TTR test model( $\mathrm{Hz})$.

\begin{tabular}{lcccrr}
\hline & $\omega_{1}$ & $\omega_{2}$ & $\omega_{3}$ & $\omega_{4}$ & $\omega_{5}$ \\
\hline$T=70 \mathrm{~N}$ & 1.2402 & 2.5008 & 3.8017 & 5.1617 & 6.5982 \\
$T=80 \mathrm{~N}$ & 1.3273 & 2.6738 & 4.0579 & 5.4976 & 7.0093 \\
$T=100 \mathrm{~N}$ & $\mathbf{1 . 4 8 5 8}$ & $\mathbf{2 . 9 8 8 7}$ & $\mathbf{4 . 5 2 5 3}$ & $\mathbf{6 . 1 1 1 9}$ & $\mathbf{7 . 7 6 3 7}$ \\
$T=120 \mathrm{~N}$ & 1.6198 & 3.2552 & 4.9217 & 6.6342 & 8.4069 \\
$T=130 \mathrm{~N}$ & 1.6879 & 3.3909 & 5.1237 & 6.9007 & 8.7358 \\
\hline
\end{tabular}

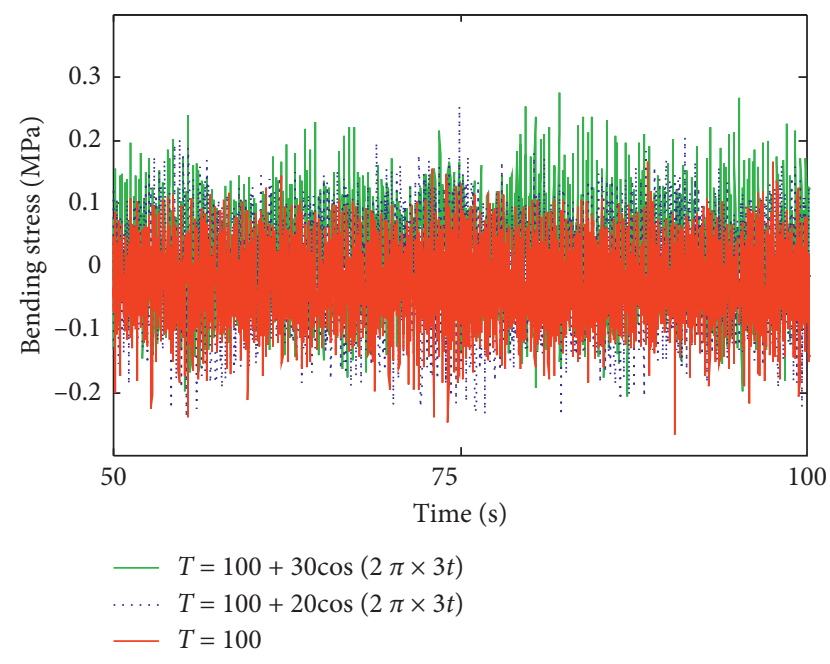

(a)

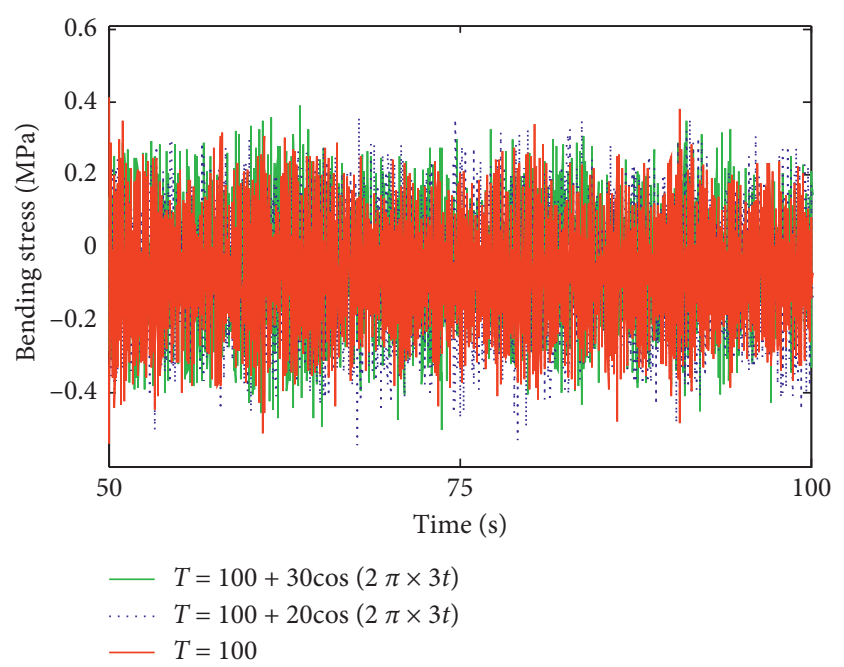

(b)

FIgURE 11: Bending stress time history of TTR at midpoint: (a) $U=0.3 \mathrm{~m} / \mathrm{s}$; (b) $U=0.5 \mathrm{~m} / \mathrm{s}$.

frequencies of TTR. It indicates that platform heave frequency is one of the dominant frequencies of TTR although the riser is controlled by VIV. Except for the platform heave frequency, the other frequencies (such as 0.5 times or 2 times of the platform heave frequency) also exist in the components of frequency of TTR due to the platform heave motion. 


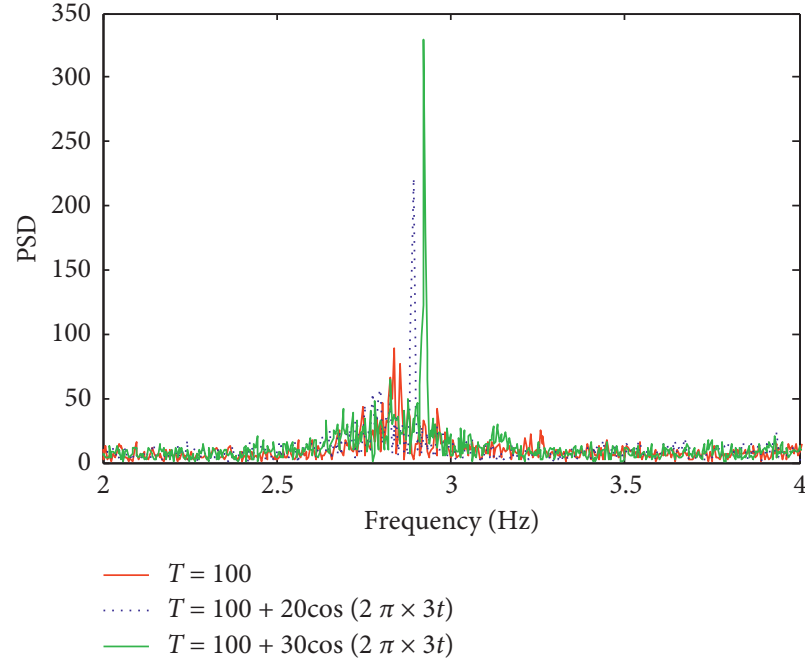

(a)

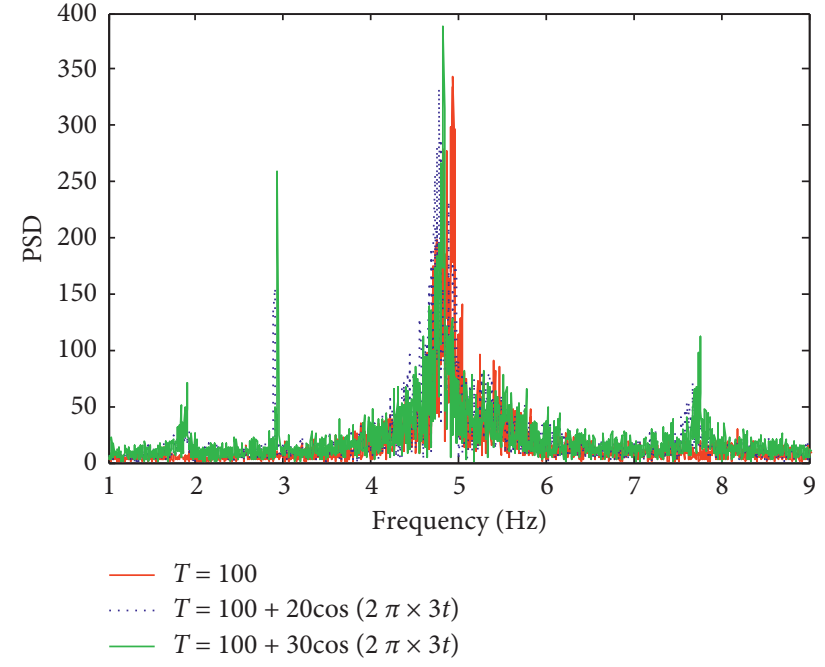

(b)

Figure 12: Frequency spectrum of TTR: (a) $U=0.3 \mathrm{~m} / \mathrm{s}$; (b) $U=0.5 \mathrm{~m} / \mathrm{s}$.
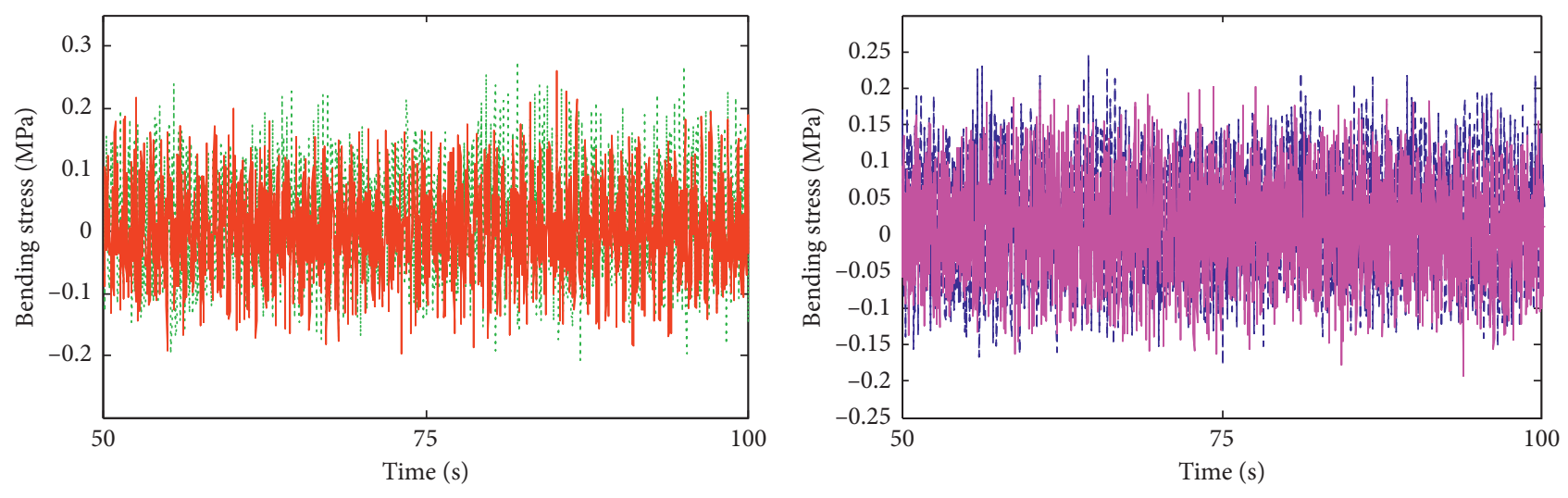

$\begin{aligned} \cdots & =3 \mathrm{~Hz} \\ \Omega & =1.5 \mathrm{~Hz}\end{aligned}$

$--\Omega=3 \mathrm{~Hz}$

$-\Omega=1 \mathrm{~Hz}$

(a)

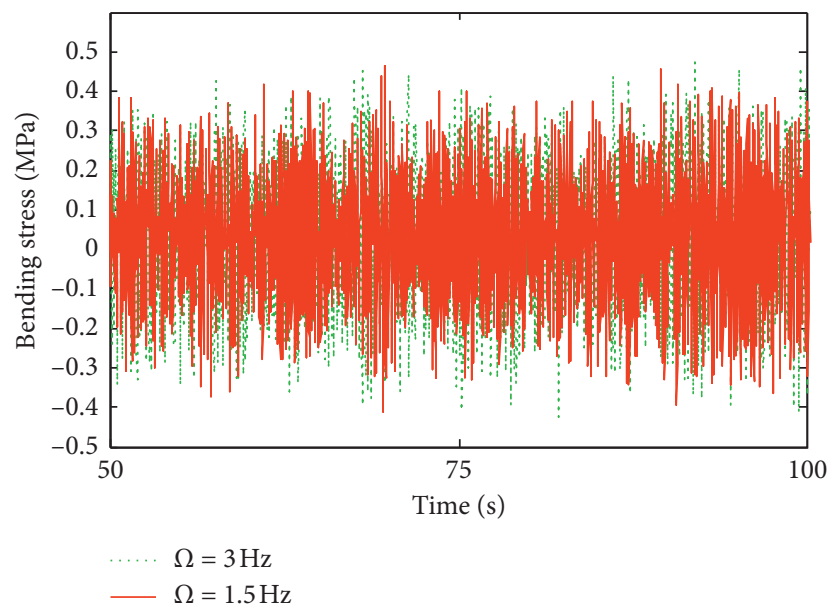

(c)

(d)

Figure 13: Bending stress time history of TTR at midpoint: (a) $U=0.3 \mathrm{~m} / \mathrm{s}, T=100 \mathrm{~N}$, and $\triangle T=30 \mathrm{~N}$; (b) $U=0.3 \mathrm{~m} / \mathrm{s}, T=100 \mathrm{~N}$, and $\triangle T=20 \mathrm{~N}$; (c) $U=0.5 \mathrm{~m} / \mathrm{s}, T=100 \mathrm{~N}$, and $\triangle T=30 \mathrm{~N}$; (d) $U=0.5 \mathrm{~m} / \mathrm{s}, T=100 \mathrm{~N}$, and $\triangle T=20 \mathrm{~N}$. 

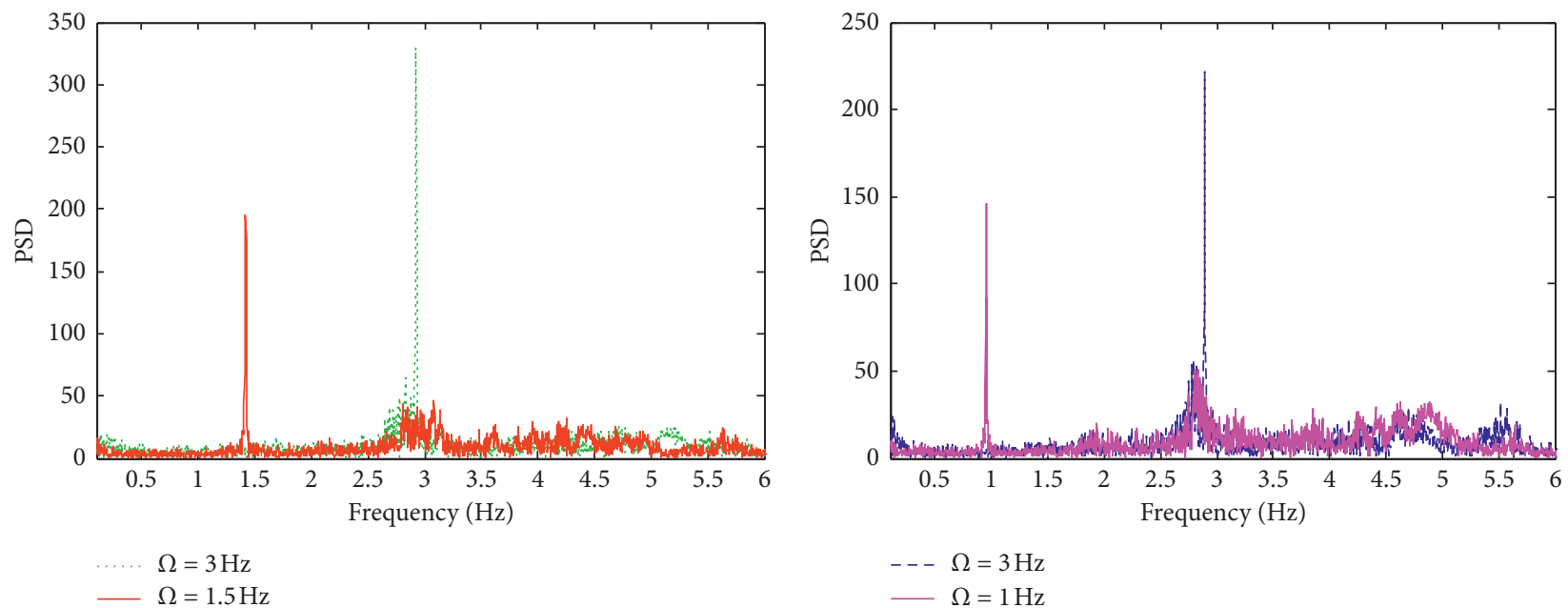

(a)

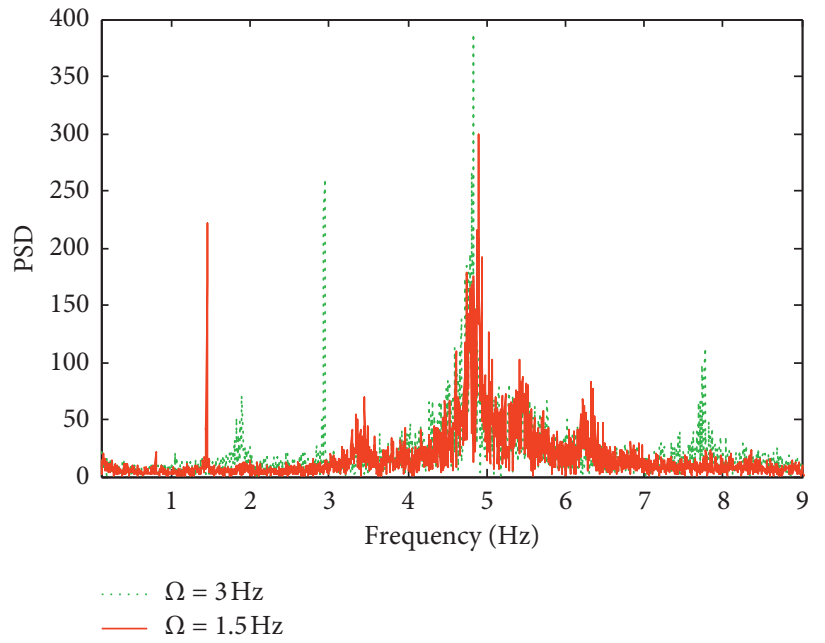

(c)

(b)

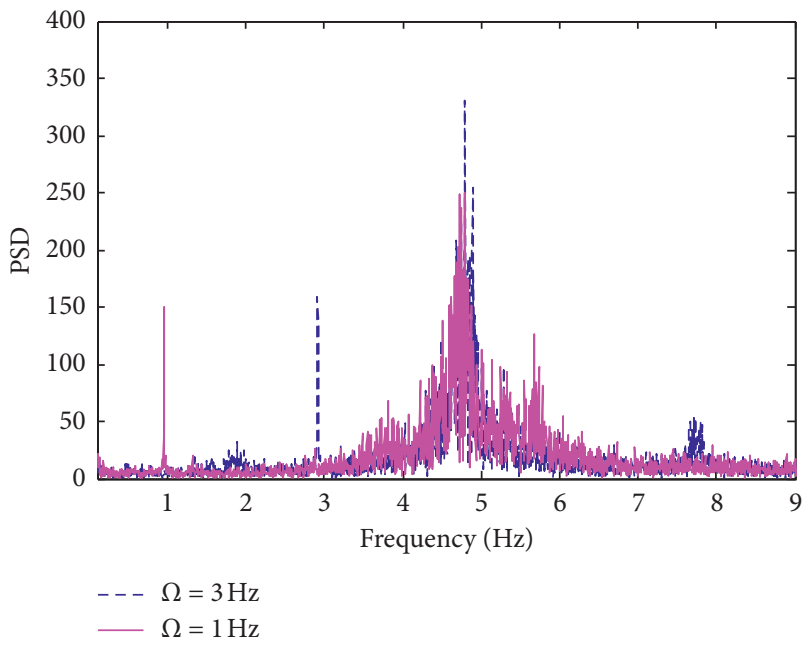

(d)

FIgURE 14: Frequency spectrum of TTR: (a) $U=0.3 \mathrm{~m} / \mathrm{s}, T=100 \mathrm{~N}$, and $\triangle T=30 \mathrm{~N}$; (b) $U=0.3 \mathrm{~m} / \mathrm{s}, T=100 \mathrm{~N}$, and $\triangle T=20 \mathrm{~N}$; (c) $U=0.5 \mathrm{~m} /$ s, $T=100 \mathrm{~N}$, and $\triangle T=30 \mathrm{~N}$; (d) $U=0.5 \mathrm{~m} / \mathrm{s}, T=100 \mathrm{~N}$, and $\triangle T=20 \mathrm{~N}$.

\section{Conclusions}

In order to study the effect of the platform heave on VIV of TTR, the platform heave motion is modeled as a parametric excitation on the top of TTR. The governing equation of VIV of TTR considering the platform heave is established, and the dynamic response of TTR is calculated numerically by FDM based on the Van der Pol wake-oscillator model. In addition, a validation experiment in the towing tank of Tianjin university is presented. The following conclusions can be drawn:

(1) The VIV response of TTR, especially in the case of lower current velocity, is much larger due to the platform heave motion. The vibration displacement and bending stress at the bottom of TTR are significantly increased considering the platform heave motion.

(2) The vibration displacement and bending stress of TTR increase as the platform heave amplitude increases. The bending stress of TTR increases as the platform heave frequency increases. However, the effect of the platform heave frequency on vibration displacement of TTR is complex, which is related to the relationship among the riser natural frequency, vortex-shedding frequency, and platform heave frequency.

(3) The dominant vibration frequency of TTR does not change significantly in the higher current since TTR is mainly controlled by VIV in this case. The frequency components of VIV of TTR change due to the platform heave motion. In particular, when the platform heave amplitude is large and the frequency is high, the value of 0.5 times, 1 time, or other multiples of the platform heave frequency will appear in the components of vibration frequencies.

\section{Data Availability}

The data used to support the findings of this study are included within the article. 


\section{Conflicts of Interest}

The authors declare that they have no conflicts of interest.

\section{Acknowledgments}

This research was supported by the National Natural Science Foundation of China (nos. 51079097 and 11601323) and State Key Laboratory of Ocean Engineering of Shanghai Jiao Tong University and Shanghai Sailing Program (no. 19YF1418500).

\section{References}

[1] K.-S. Hong and U. H. Shah, "Vortex-induced vibrations and control of marine risers: a review," Ocean Engineering, vol. 152, pp. 300-315, 2018.

[2] A. Moghiseh, H. R. Chaloshtory, and A. Rahi, "Effect of middle tension on dynamic behaviour of marine risers," Journal of Maritime Research, vol. 9, no. 1, pp. 63-70, 2012.

[3] A. D. Trim, H. Braaten, H. Lie, and M. A. Tognarelli, "Experimental investigation of vortex-induced vibration of long marine risers," Journal of Fluids and Structures, vol. 21, no. 3, pp. 335-361, 2005.

[4] O. M. Griffin and S. E. Ramberg, "Some recent studies of vortex shedding with application to marine tubulars and risers," Journal of Energy Resources Technology, vol. 104, no. 1, pp. 2-13, 1982.

[5] R. D. Gabbai and H. Benaroya, "An overview of modeling and experiments of vortex-induced vibration of circular cylinders," Journal of Sound and Vibration, vol. 282, no. 3-5, pp. 575-616, 2005.

[6] X. Wu, F. Ge, and Y. Hong, "A review of recent studies on vortex-induced vibrations of long slender cylinders," Journal of Fluids and Structures, vol. 28, pp. 292-308, 2012.

[7] N. Srinil, "Analysis and prediction of vortex-induced vibrations of variable-tension vertical risers in linearly sheared currents," Applied Ocean Research, vol. 33, no. 1, pp. 41-53, 2011.

[8] E. Wang and Q. Xiao, "Numerical simulation of vortex-induced vibration of a vertical riser in uniform and linearly sheared currents," Ocean Engineering, vol. 121, pp. 492-515, 2016.

[9] J. V. Ulveseter, S. Sævik, and C. M. Larsen, "Time domain model for calculation of pure in-line vortex-induced vibrations," Journal of Fluids and Structures, vol. 68, pp. 158-173, 2017.

[10] M. J. Thorsen, S. Sævik, and C. M. Larsen, "Fatigue damage from time domain simulation of combined in-line and crossflow vortex-induced vibrations," Marine Structures, vol. 41, pp. 200-222, 2015.

[11] H. Xue, K. Wang, and W. Tang, "A practical approach to predicting cross-flow and in-line VIV response for deepwater risers," Applied Ocean Research, vol. 52, pp. 92-101, 2015.

[12] Y. Yuan, H. Xue, and W. Tang, "An improved time domain coupled model of Cross-Flow and In-Line Vortex-Induced Vibration for flexible risers," Ocean Engineering, vol. 136, pp. 117128, 2017.

[13] W. Chen, M. Li, Z. Zheng, S. Guo, and K. Gan, "Impacts of top-end vessel sway on vortex-induced vibration of the submarine riser for a floating platform in deep water," Ocean Engineering, vol. 99, pp. 1-8, 2015.

[14] H. Guo, L. Zhang, X. Li, and M. Lou, "Dynamic responses of top tensioned riser under combined excitation of internal solitary wave, surface wave and vessel motion," Journal of Ocean University of China, vol. 12, no. 1, pp. 6-12, 2013.

[15] H. Fan, C. Li, Z. Wang, L. Xu, Y. Wang, and X. Feng, "Dynamic analysis of a hang-off drilling riser considering internal solitary wave and vessel motion," Journal of Natural Gas Science and Engineering, vol. 37, pp. 512-522, 2017.

[16] J. Wang, S. Xiang, S. Fu, P. Cao, J. Yang, and J. He, "Experimental investigation on the dynamic responses of a freehanging water intake riser under vessel motion," Marine Structures, vol. 50, pp. 1-19, 2016.

[17] D. Yin, E. Passano, H. Lie et al., "Experimental and numerical study of a top tensioned riser subjected to vessel motion," Ocean Engineering, vol. 171, pp. 565-574, 2019.

[18] Y. Gao, Fatigue damage analysis of steel catenary riser, $\mathrm{PhD}$ Thesis, Dalian University of Technology, Dalian, China, 2011.

[19] D. Y. Wang and G. C. Ling, "Vortex-induced nonlinear vibration of TLP tethers under circumstances of platform oscillation," Acta Oceanol Sin, vol. 20, no. 3, pp. 119-128, 1998.

[20] M. J. Thorsen and S. Sævik, "Vortex-induced vibrations of a vertical riser with time-varying tension," Procedia Engineering, vol. 199, pp. 1326-1331, 2017.

[21] G. L. Kuiper, J. Brugmans, and A. V. Metrikine, "Destabilization of deep-water risers by a heaving platform," Journal of Sound and Vibration, vol. 310, no. 3, pp. 541-557, 2008.

[22] J. Zhang and Y. Tang, "Parametric instability analysis of deepwater top-tensioned risers considering variable tension along the length," Journal of Ocean University of China, vol. 14, no. 1, pp. 59-64, 2015.

[23] J. Zhang, H. Guo, Y. Tang, and Y. Li, "Effect of top tension on vortex-induced vibration of deep-sea risers," Journal of Marine Science and Engineering, vol. 8, no. 2, pp. 121-2, 2020.

[24] M. L. Facchinetti, E. de Langre, and F. Biolley, "Coupling of structure and wake oscillators in vortex-induced vibrations," Journal of Fluids and Structures, vol. 19, no. 2, pp. 123-140, 2004.

[25] H. Zanganeh and N. Srinil, "Three-dimensional VIV prediction model for a long flexible cylinder with axial dynamics and mean drag magnifications," Journal of Fluids and Structures, vol. 66, pp. 127-146, 2016.

[26] X. Chang, J. Fan, W. Yang, and Y. Li, "In-line and cross-flow coupling vibration response characteristics of a marine viscoelastic riser subjected to two-phase internal flow," Shock and Vibration, vol. 2021, Article ID 7866802, 27 pages, 2021.

[27] T. P. Basil, "Numerical simulation of the truss spar horn moutain using couple," Master's Thesis, Texas A\&M University, College Station, TX, USA, 2006.

[28] J. Zhang and Y. G. Tang, "Further analysis on natural vibration of deep-water risers," Journal of Ship Mechanics, vol. 18, no. 1-2, pp. 165-171, 2014.

[29] W. P. Huang, C. D. Sun, S. Z. Tang, C. Liu, and J. Cao, "Study on wave-induced fatigue of deep water production TTR," China Offshore Platform, vol. 24, no. 3, pp. 26-30, 2009.

[30] W. J. Shen, Study on the nonlinear stochastic dynamic response characteristics of a truss spar, $\mathrm{PhD}$ Thesis, Tianjin university, Tianjin, China, 2012.

[31] Y. Gao, Z. Zong, and L. Sun, "Numerical prediction of fatigue damage in steel catenary riser due to vortex-induced vibration," Journal of Hydrodynamics, vol. 23, no. 2, pp. 154-163, 2011. 